\title{
Mulheres e os livros de projetos integradores em Ciências da Natureza
}

\author{
Women and the textbooks in integratives projects of Natural Science \\ Mujeres e los libros didácticos de proyectos integrativos en Ciencias \\ Naturales \\ Thaynara Beatriz Selasco de Matos ${ }^{1}$; Ana Cecilia Soja ${ }^{2}$
}

\section{RESUMO}

Ao longo da História mulheres foram impedidas de participar da Educação formal, cenário que tem se alterado nas últimas décadas. Hoje na maior parte do mundo todos têm direito ao ensino. Resolvido isso, busca-se o reconhecimento, já que a contribuição de mulheres ainda é pouco reconhecida. Autoras como Rosa e Silva (2015) e Bianchi (2020) mostraram que tal apagamento se reflete no livro didático. O presente trabalho teve como objetivo investigar a representatividade feminina nos livros de projetos integradores em Ciências da Natureza do novo Programa Nacional do Livro Didático (PNLD) de 2021. Numa abordagem qualitativaquantitativa, analisou-se a equidade de gênero em cinco parâmetros: representação nas imagens, número de autoras, referências, citações e equipe técnica. $O$ resultado foi positivo para imagens, autoria e equipe técnica. Além disso, verificou-se que o protagonismo feminino no ativismo social/ambiental era exaltado. Entretanto, contradições persistem, dada a desproporcionalidade de referências e citações de mulheres quando a produção acadêmica já atingiu a equidade. Assim, mostramos que há avanços, mas que a discussão deve seguir até que alcancemos a equidade.

Palavras-chave: Ensino de Ciências da Natureza; Livros didáticos; Mulheres na Ciência.

\begin{abstract}
Throughout history, women have been prevented from participating in formal education, a scenario that has changed in recent decades. Today everyone has the right to education in most of the world. Once it was resolved, the next step is recognition since the contribution of women is still little recognized. Authors such as Rosa and Silva (2015) and Bianchi (2020) showed that the problem is reflected in the textbook. The present work aimed to investigate the female representation in the books of Integrative Projects in Natural Sciences of the new National Textbook Program (PNLD, in Portuguese) of 2021. In a qualitative-quantitative approach, gender equity was analyzed in five parameters: representation in images, number of authors, references, citations and technical team. The result was positive for images, authors and staff. In addition, it was found that the female protagonism in social/environmental activism was exalted. However, contradictions persist, given the disproportionality of references and citations from women when academic production has reached equity. Thus, we show that there is progress, but that the discussion must continue until we reach equity.
\end{abstract}

Keywords: Science Teaching; Science textbooks; Women in Science.

\footnotetext{
${ }^{1}$ Técnica em Informática e monitora do projeto de extensão Ciência na Fronteira: Expandindo os Limites do Conhecimento, Instituto Federal do Mato Grosso do Sul (IFMS), Corumbá/MS - Brasil. E-mail: thaynara.matos2015@gmail.com

2 Bacharel em Física, Mestra e Doutora em Ciências e Professora do Instituto Federal do Mato Grosso do Sul (IFMS), Corumbá/MS - Brasil. E-mail: ac.soja@gmail.com
} 


\section{RESUMEN}

A lo largo de la historia se impidió que las mujeres participasen en la educación formal, el escenario cambió en las últimas décadas. Hoy, todos tienen derecho a la educación en la mayor parte del mundo. El siguiente paso es el reconocimiento, pues las mujeres aún son poco reconocidas. Autores como Rosa e Silva (2015) y Bianchi (2020) demostraron que eso se refleja en el libro didáctico. El presente trabajo tuvo como objetivo investigar la representación femenina en los libros de Proyectos Integrativos en Ciencias Naturales del nuevo Programa Nacional de Libros de Texto (PNLD) de 2021. En un enfoque cualitativo-cuantitativo, se estudió la equidad de género en cinco parámetros: representación en imágenes, número de autores, referencias, citas y equipo técnico. El resultado fue positivo para imágenes, autores y equipo técnico. Además, se constató que se exaltaba el protagonismo femenino en el activismo socioambiental. Sin embargo, persisten las contradicciones, dada la desproporcionalidad de referencias y citas de mujeres cuando la producción académica alcanza la equidad. Así, mostramos que hay avanzos, pero que la discusión debe continuar hasta llegar a la equidad.

Palabras clave: Enseñanza de la ciencia; libros de ciencia; mujeres en la ciencia.

\section{INTRODUÇÃO}

A educação, em geral, manteve-se com viés elitista e sexista durante a maior parte de sua história (ROSA \& SILVA, 2015). Na Antiguidade, por exemplo, até mesmo mulheres de classes privilegiadas foram relacionadas à maternidade, ao matrimônio e ao ambiente doméstico, de maneira que se mantiveram, em sua maioria, afastadas de questões intelectuais. Todavia, há aquelas que de alguma forma conseguiram, mesmo com todas as dificuldades, fazer Ciência. Uma destas, conforme Diedrich (2018), é Theano, física, matemática e filósofa da Grécia Antiga que, apesar de ser uma inspiração em potencial, é pouco lembrada no meio escolar. Rosa e Silva (2015), citando as autoras Barbosa e Lima (2013), demonstra que todo o processo histórico da desigualdade entre homens e mulheres influenciou, inclusive, a educação. Além da introdução tardia das mulheres nas universidades, mais especificamente em meados do século XIX, estas eram induzidas a seguir carreiras distantes das áreas das ciências, impacto que é perceptível ainda nos dias atuais com o atraso da participação feminina nesta área no Brasil e no mundo. Dessa forma, é expectável que as dimensões de ensino às mulheres sejam desproporcionais, visto que inúmeras destas foram apagadas e distanciadas em diferentes contextos no decorrer dos séculos.

No que tange à educação feminina, é comum que estas tenham seus itinerários moldados, limitados e condicionados de modo a atender as expectativas da sociedade. O conceito de exclusão horizontal que, de acordo com Lima (2008, p.8), trata da "divisão de áreas do conhecimento caracterizadas em femininas ou masculinas nas ciências", decorre de imposições sociais que impedem meninas de adentrarem onde há predominância masculina como, por exemplo, na Física. Consoante a Barbosa (2015), conforme citado por Bianchi (2020), há uma diferença significativa entre as quantidades de homens e mulheres que atuam na área da Física, fenômeno decorrente do machismo e da misoginia que operam na separação de funções sociais para cada gênero. Para a autora, tal problemática apenas atrasaria os resultados, pois as mulheres, enquanto seres tão intelectualmente capazes quanto os homens, não poderiam contribuir e seriam menos pessoas trabalhando na produção científica. Além disso, afirma que:

Preconceitos de gênero afetam a escolha do objeto de investigação e a forma de investigação - alteram a maneira de produzir ciência, pois reduzem a diversidade de possibilidades de pensar sobre um mesmo problema. (BIANCHI, 2020, p.5) 
Nessa lógica, é de fácil observação a indiferença com que são tratadas as conquistas femininas quando comparadas com a visibilidade dada à dos homens. Em seu estudo, Bianchi (2020) afirma que as descobertas feitas por mulheres são destacadas esporadicamente, ou seja, em eventos isolados como programas de inclusão de mulheres na Ciência e textos especiais sobre o assunto, por exemplo; muitas vezes associadas apenas a datas comemorativas.

Dessa maneira, o livro didático (LD) é visto como um excelente instrumento para a propagação das realizações de cientistas, posto que alcança significativamente o público jovem em formação e, conforme Rosa e Silva (2015), é também uma forma de representatividade. Entretanto, é observado uma diferença expressiva entre o quantitativo de citações dos dois gêneros. A autora diz ainda que o livro didático tem relevante participação na propagação das contribuições científicas durante o Ensino Médio - pois "é uma das formas pela qual os e as estudantes terão contato frequente com o conhecimento científico" - e que a ausência das mulheres nos LDs pode atuar como incentivo para a desigualdade de gênero.

Mas qual a importância dos livros didáticos? Por que exemplificar as realizações de mulheres neles? Estas perguntas podem ser respondidas ao pensar em como esses LDs atuam como um espelho, transparecendo muitos dos costumes inerentes à sociedade. Os livros didáticos, para Bianchi (2020, p.3), refletem fatores da comunidade pois "são produzidos por grupos sociais e sofrem influência da cultura, das desigualdades e das disputas desse mesmo povo". A pesquisadora Rosa e Silva (2015) vê como possível consequência da ausência de figuras femininas nestes LDs o afastamento entre as meninas e a Ciência, visto que, quando representadas, são associadas a tarefas socialmente destinadas a mulheres, tais como cuidar da casa e dos filhos. Assim, os estereótipos baseados nas construções de gêneros são espelhados no conteúdo. Portanto, o machismo e misoginia se mostram presentes, uma vez que, quando citadas nos LDs, os aspectos da vida pessoal de cada cientista recebem mais atenção do que, por exemplo, o caminho científico que a mulher percorreu antes de alcançar a devida conquista, ou, simplesmente realizam a citação ausente de qualquer detalhamento. Para exemplificar tal afirmação:

Outro exemplo relevante é o de Marie Curie, que é a mulher mais citada nos livros de Física e de Química. Em um dos livros, uma página sobre Marie tem aproximadamente metade do espaço do texto voltado a enfatizar seu papel de esposa e mãe, e de professora do que seria o equivalente ao ensino médio, mesmo sendo ela uma pesquisadora na área experimental, a primeira pessoa a receber dois prêmios Nobel e a primeira mulher a lecionar em uma universidade (BIANCHI, 2019, p.5).

Neste contexto se insere o novo Programa Nacional do Livro Didático (PNLD), que realiza a distribuição de livros de apoio para escolas públicas que participam do programa e, consequentemente, carrega consigo a responsabilidade de auxiliar os professores no cotidiano escolar. Esse material funciona como subsídio para a implementação da Base Nacional Comum Curricular (BNCC), que determina todo o conteúdo essencial e indispensável que os estudantes deverão ter acesso durante cada etapa da Educação Básica, seja em escolas públicas ou privadas. Ademais, o novo PNLD segue a reforma do Ensino Médio e com isso, conforme o Guia Digital do PNLD (MEC, 2021), "espera-se que a escola se organize para acolher as culturas juvenis atuais e considere os diferentes perfis de seus estudantes, respeitando seus direitos, singularidades, interesses e aspirações".

À vista disso, de acordo com o Guia Digital do PNLD (2021), no que se trata de questões de gênero, o material didático distribuído tem o dever de garantir a visibilidade e protagonismo das mulheres nas atividades, "considerando sua participação em diferentes trabalhos, profissões e espaços de poder, 
no intuito de valorizar seus saberes e sua cultura". Deve também seguir princípios éticos que determinam a ausência de qualquer tipo de discriminação ou preconceito, para que não haja a violação dos direitos humanos. E, consequentemente, por seguir a BNCC, deve auxiliar no desenvolvimento da seguinte habilidade:

Discutir e analisar as causas da violência contra populações marginalizadas (negros, indígenas, mulheres, homossexuais, camponeses, pobres etc.) com vistas à tomada de consciência e à construção de uma cultura de paz, empatia e respeito às pessoas (BNCC, 2020, p.431).

Dado o acima exposto, o objetivo desta pesquisa é investigar se as diretrizes de igualdade de gênero estão sendo seguidas nos livros de Ciências da Natureza e comparar nossos resultados com levantamentos prévios supracitados. Para tanto, foram escolhidos parâmetros que nos possibilitem verificar a quantidade e a forma com que o trabalho de mulheres, cientistas ou não, são apresentados nestes livros, os quais serão melhor explicados a seguir.

O trabalho se organiza da seguinte maneira: na próxima seção serão apresentadas a base de dados e a metodologia escolhida. Em seguida, são sistematizados os resultados e respectivas observações. Por fim, discute-se as principais conclusões e perspectivas do estudo.

\section{Metodologia}

Esta pesquisa é um estudo de caso de natureza aplicada e tem por fito analisar a presença feminina nos novos livros didáticos (LDs) dos projetos integradores de Ciências da Natureza através de procedimentos bibliográficos e, primordialmente, documentais, utilizando uma abordagem qualitativaquantitativa (PRODANOV, 2013).

Os projetos integradores são uma nova modalidade prevista na reforma do Ensino Médio que está em andamento. Seu objetivo é proporcionar uma aprendizagem baseada em projetos (p.e., MAGALHÃES \& PEREIRA, 2019) que trata o assunto estudado numa perspectiva holística, englobando vários aspectos da vida do estudante. A escolha desses livros em específico se deu porque eles surgem com uma proposta de revolucionar os olhares tradicionais sobre ensino e conhecimento. Logo, é interessante verificar se as questões de gênero já observadas como problemáticas em livros tradicionais são melhor trabalhadas nesse novo modelo.

Os 13 livros que compõem o acervo analisado fazem parte do novo PNLD de 2021 e seguem a BNCC e a Reforma do Ensino Médio em andamento desde 2017 (BRASIL, 2017). Distribuídos por 9 diferentes editoras (tabela 1), os livros têm como proposta a educação por meio de Projetos Integradores que visam, além de aproximar os estudantes de causas reais através de um aprendizado ativo, auxiliar no desenvolvimento de habilidades como a comunicação e argumentação. Em geral, os LDs possuem 6 módulos, nos quais os assuntos podem variar dentro de temas pré-estabelecidos. 
Tabela 1 - Relação dos livros e seus respectivos dados

\begin{tabular}{|c|c|c|c|}
\hline APELIDO & TÍTULO & EDITORA & CÓDIGO \\
\hline ÁTICA & $\begin{array}{l}\text { DE OLHO NO FUTURO - PROJETOS INTEGRADORES - } \\
\text { CIÊNCIAS DA NATUREZA E SUAS TECNOLOGIAS }\end{array}$ & $\begin{array}{l}\text { EDITORA } \\
\text { ÁTICA S.A. }\end{array}$ & $\begin{array}{r}0070 P 2150 \\
7\end{array}$ \\
\hline BRASIL1 & $\begin{array}{l}\text { CONHECER E TRANSFORMAR: PROJETOS } \\
\text { INTEGRADORES }\end{array}$ & $\begin{array}{l}\text { EDITORA } \\
\text { DO BRASIL }\end{array}$ & $\begin{array}{r}0008 \mathrm{P} 2150 \\
7\end{array}$ \\
\hline BRASIL2 & INTEGRAÇÃO E PROTAGONISMO & $\begin{array}{l}\text { EDITORA } \\
\text { DO BRASIL }\end{array}$ & $\begin{array}{r}0082 \mathrm{P} 2150 \\
7\end{array}$ \\
\hline FTD & $\begin{array}{l}\text { AÇÃO NA ESCOLA E NA COMUNIDADE - PROJETOS } \\
\text { INTEGRADORES - CIÊNCIAS DA NATUREZA E SUAS } \\
\text { TECNOLOGIAS }\end{array}$ & $\begin{array}{l}\text { EDITORA } \\
\text { FTD S.A. }\end{array}$ & $\begin{array}{r}0086 \mathrm{P} 2150 \\
7\end{array}$ \\
\hline INTEGRALIS & $\begin{array}{l}\text { INTEGRALIS - CIÊNCIAS DA NATUREZA E SUAS } \\
\text { TECNOLOGIAS - PROJETOS INTEGRADORES }\end{array}$ & IBEP & $\begin{array}{r}0062 P 2150 \\
7\end{array}$ \\
\hline MODERNA 1 & $\begin{array}{l}\text { MODERNA EM PROJETOS: CIÊNCIAS DA NATUREZA E } \\
\text { SUAS TECNOLOGIAS }\end{array}$ & $\begin{array}{l}\text { EDITORA } \\
\text { MODERNA }\end{array}$ & $\begin{array}{r}0025 P 2150 \\
7\end{array}$ \\
\hline MODERNA 2 & $\begin{array}{l}\text { PRÁTICAS NA ESCOLA - CIÊNCIAS DA NATUREZA E SUAS } \\
\text { TECNOLOGIAS }\end{array}$ & $\begin{array}{l}\text { EDITORA } \\
\text { MODERNA }\end{array}$ & $\begin{array}{r}0031 P 2150 \\
7\end{array}$ \\
\hline MODERNA 3 & $\begin{array}{l}\text { IDENTIDADE EM AÇÃO: CIÊNCIAS DA NATUREZA E SUAS } \\
\text { TECNOLOGIAS }\end{array}$ & $\begin{array}{l}\text { EDITORA } \\
\text { MODERNA }\end{array}$ & $\begin{array}{r}0033 P 2150 \\
7\end{array}$ \\
\hline SARAIVA & $\begin{array}{l}\text { VAMOS JUNTOS, PROFE! - PROJETOS INTEGRADORES - } \\
\text { CIÊNCIAS DA NATUREZA E SUAS TECNOLOGIAS }\end{array}$ & $\begin{array}{l}\text { SARAIVA } \\
\text { EDUCAÇÃO }\end{array}$ & $\begin{array}{r}0057 P 2150 \\
7\end{array}$ \\
\hline SCIPIONE & $\begin{array}{l}\text { \#NOVO ENSINO MÉDIO - PROJETOS INTEGRADORES - } \\
\text { CIÊNCIAS DA NATUREZA E SUAS TECNOLOGIAS }\end{array}$ & $\begin{array}{l}\text { EDITORA } \\
\text { SCIPIONE }\end{array}$ & $\begin{array}{r}0037 P 2150 \\
7\end{array}$ \\
\hline SM1 & $\begin{array}{l}\text { JOVEM PROTAGONISTA PROJETOS INTEGRADORES } \\
\text { CIÊNCIAS DA NATUREZA E SUAS TECNOLOGIAS }\end{array}$ & $\begin{array}{l}\text { EDIÇÕES } \\
\text { SM LTDA. }\end{array}$ & $\begin{array}{r}0048 P 2150 \\
7\end{array}$ \\
\hline SM2 & $\begin{array}{l}\text { SER PROTAGONISTA PROJETOS INTEGRADORES } \\
\text { CIÊNCIAS DA NATUREZA E SUAS TECNOLOGIAS }\end{array}$ & $\begin{array}{l}\text { EDIÇÕES } \\
\text { SM LTDA. }\end{array}$ & $\begin{array}{r}0051 P 2150 \\
7\end{array}$ \\
\hline UNIVERSO & $\begin{array}{l}\text { PROJETOS INTEGRADORES: INTEGRANDO SABERES - } \\
\text { CIÊNCIAS DA NATUREZA }\end{array}$ & $\begin{array}{l}\text { UNIVERSO } \\
\text { DOS } \\
\text { LIVROS } \\
\text { EDITORA }\end{array}$ & $\begin{array}{r}0043 P 2150 \\
7\end{array}$ \\
\hline
\end{tabular}

Fonte: Elaborada pelas autoras, 2021. 
Definida a base de dados e sua relevância, seguiu-se a escolha dos parâmetros. Eles foram divididos entre visuais (análise de imagens), referencias (citações e referências) e técnico (análise da equipe que construiu o livro). Tal divisão visa cobrir todos os aspectos da construção de um material didático e impacta de maneira diferente o leitor final (aluno). Por exemplo, as imagens afetam mais diretamente os estudantes, pois eles são submetidos a elas apenas ao folhear o livro e mesmo que inconscientemente registram as informações lá contidas. Assim, se nessas imagens há equidade de homens e mulheres representados e também igualdade em suas posições, é de se esperar que os estudantes naturalizem a presença feminina em ambientes científicos, fazendo com que essas imagens cumpram por si só uma função didática (Farias e Faheina, 2018). Já os aspectos de referência e equipe são menos perceptíveis pelos estudantes, uma vez que não é hábito que os autores e a equipe técnica sejam analisados ou discutidos ao pegarmos um livro. Porém, eles são importantes também pois refletem se houve preocupação das editoras em valorizar o trabalho e a produção acadêmica de mulheres na construção do seu material; em outras palavras, se a inclusão foi além do visível e de fato integrada ao projeto (Magalhães et al. 2017).

A seguir, detalhamos os cinco parâmetros - divididos nas três categorias, - que fizeram parte de nossa análise:

\section{a) Imagens:}

Conforme defendido por Belmiro (2000), o uso dessa ferramenta, ora possibilita a visão por novas perspectivas, utilizando o máximo dos sentidos na absorção do conhecimento, ora trabalha com a aproximação do interlocutor. A autora demonstra a importância das imagens mesmo no âmbito da estética, no qual elas servem não só para ilustrar os cenários e incentivar a imaginação, mas também trabalham na quebra do ritmo cansativo de leitura. Ao citar Maffesoli (1995), reforça o poder desse mecanismo no processo de recorrência ao cotidiano, que torna possível o autorreconhecimento do público por meio de características que os ligam aos seus respectivos grupos sociais. Ademais, tal identificação por meio dos estudantes traz representatividade para o material, além de proporcionar melhorias na transmissão da enunciação da imagem.

Dado sua importância, a análise das imagens foi dividida em duas partes: qualitativa e quantitativa. Na primeira, o objetivo era investigar como essas mulheres eram representadas nos livros, ou seja, se eram vistas em situações diversas ou restritas a estereótipos de gênero - como apontado no trabalho de Rosa e Silva (2015). Já a segunda abordagem visava verificar se homens e mulheres eram igualmente representados do ponto de vista quantitativo, fator importante para que a participação da mulher seja naturalizada tal qual a do homem.

\section{b) Autoras:}

Relativo ao contexto já explicado da existência de um sistema que valoriza e prioriza a masculinidade em diversas áreas da nossa sociedade incluindo a Educação, o surgimento de uma escrita feminina reconhecida, ainda que sem receber a devida importância, surgiu tardiamente no século XVIII. Ainda que Diniz (2014) se refira a obras literárias, sua reflexão cabe também à questões de quaisquer produções femininas, na medida que, para ela, restringir mulheres da escrita é tirar-lhes a propriedade da fala - "as mulheres não conseguem dizer quem são, para que vieram e porque vieram ao mundo" (DINIZ, 2014, p.58). Em um primeiro momento, incentivar a valorização de obras produzidas por mulheres é compensar todo o atraso histórico a que foram submetidas e deixar que elas possam transparecer suas vivências em forma de problemáticas de gêneros quando forem necessárias. 
Tendo isso em vista, escolhemos realizar a análise da presença feminina no texto a partir da contagem da quantidade de mulheres que auxiliaram na produção do material didático em comparação com a quantidade de homens.

\title{
c) Referências:
}

A ideia de usar as referências dos livros como parâmetros para a análise segue a mesma linha de raciocínio vista no tópico anterior a respeito da valorização das produções femininas. Consoante a Siqueira (2019, p.20), "há uma necessidade das mulheres se fazerem presentes na construção deste tipo de obra, para assim reivindicarem o seu espaço em todas as esferas da educação brasileira". As referências foram variáveis importantes pois, caso haja escassez, demonstram o quão despercebidas essas mulheres têm passado. Por esse motivo, foi calculada a porcentagem de trabalhos referenciados que continham mulheres em sua autoria.

\section{d) Citações:}

As citações de mulheres nos LDs são capazes de aproximar a Ciência das novas gerações, uma vez que mostra que ela está ao alcance de todos. Assim:

\begin{abstract}
Mostrar como elas ocuparam e tiveram participação nas diversas dinâmicas históricas produz uma nova mentalidade acerca dos espaços sociais ocupados por elas, além de gerar representatividade e a apresentação de possibilidades reais de romper com o destino que é colocado ao gênero feminino. (SIQUEIRA, 2019, p.46)
\end{abstract}

Citar cientistas mulheres, sejam elas do passado ou do presente, é lutar contra o apagamento constante a que estas são submetidas e persistir em um processo que pretende mudar o imaginário das pessoas ao pensarem em quem produz Ciência. Nesse sentido, foram analisadas a porcentagem de mulheres citadas em cada um dos livros.

\section{e) Equipe técnica:}

Na cartilha Princípios de Empoderamento das Mulheres (2017) desenvolvida pela ONU Mulheres Brasil e a Rede Brasil do Pacto Global, ressalta-se a importância de ter mulheres em papéis de liderança e destaque nos mais variados setores. Nesse sentido, uma das maneiras ativas de lutar contra a desigualdade de gênero é fornecer oportunidades igualitárias, que neste caso são dadas mediante a participação na elaboração do material completo. O produto final que possui grande discrepância na divisão do trabalho por gênero cria, portanto, baixas expectativas de que tenha sido planejado pensando nos problemas de gênero. Logo, analisar a porcentagem feminina na equipe é parte da nossa abordagem, uma vez que objetivamos verificar a equidade de gênero como um todo.

Dado o exposto, foi realizada então a análise dos LDs em si a partir dos parâmetros citados. Os resultados obtidos são explorados na próxima seção.

\section{RESULTADOS E DISCUSSÃO}

Considerando os parâmetros definidos, os 13 livros foram analisados página a página. Seguindo a ordem, o primeiro parâmetro foi o estudo das imagens. Logo nessa primeira etapa, verificou-se que algumas variáveis eram desnecessárias. Por exemplo, uma das características propostas seria classificar as imagens que continham mulheres entre positivas e negativas, com a expectativa de decodificar a forma com que essas foram representadas, assim como realizado na pesquisa de Rosa 
e Silva (2015). Entretanto, um dos fatores comuns entre os livros é a ausência de imagens que restringiam mulheres a papéis específicos e estereotipados; ao contrário, verificou-se muitos exemplos de imagens de mulheres em situações diversificadas, conforme exemplificado nas Figuras 1 e 2.

Figura 1 - Fotografia. Jovens fazendo carrinho manualmente.

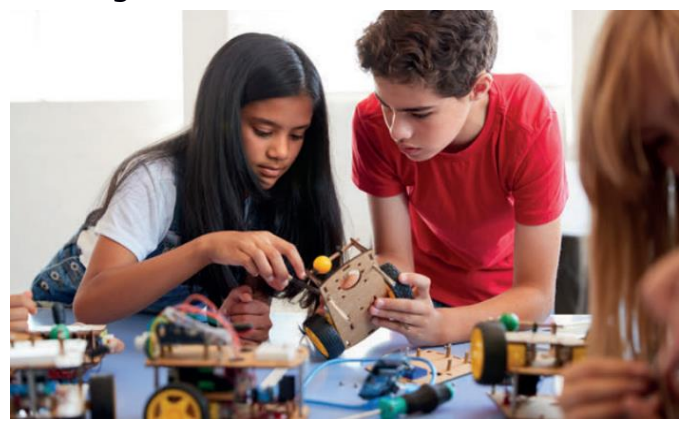

Fonte: Extraído do livro Integralis, p. 143

Figura 2 - Fotografia. Time feminino de basquete.

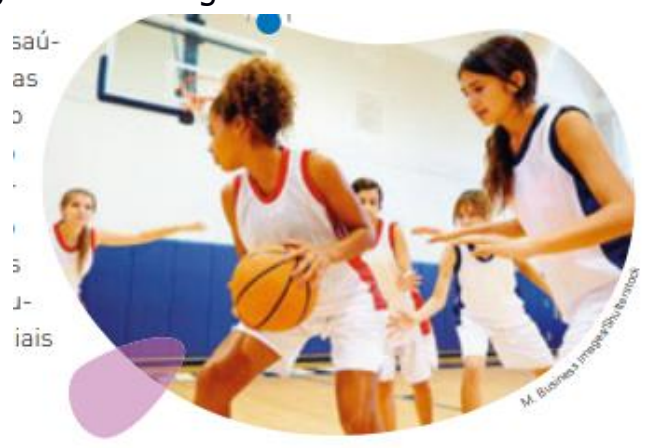

Fonte: Extraído do livro Ática, p. 92.

O estudo de Rosa e Silva (2015) serviu ainda como meio de comparação, haja vista que tais autoras observaram que apenas $21 \%$ da totalidade de recursos visuais encontrados continham mulheres. $\mathrm{Na}$ presente pesquisa, todavia, vê-se a proporção melhor distribuída tanto individualmente quanto em sua completude. Das 754 imagens examinadas, 529 dispõem de ao menos 1 mulher, representando, portanto, $70 \%$ das imagens, o que representa 3,5 vezes a mais do que nos livros averiguados pelo estudo citado. O Gráfico 1 a seguir mostra a distribuição individual das imagens por livro. Nele verificase que essa proporção equilibrada é uma tendência entre todas as editoras, com nenhum caso discrepante identificado.

Gráfico 1 - Distribuição individual das imagens por livro

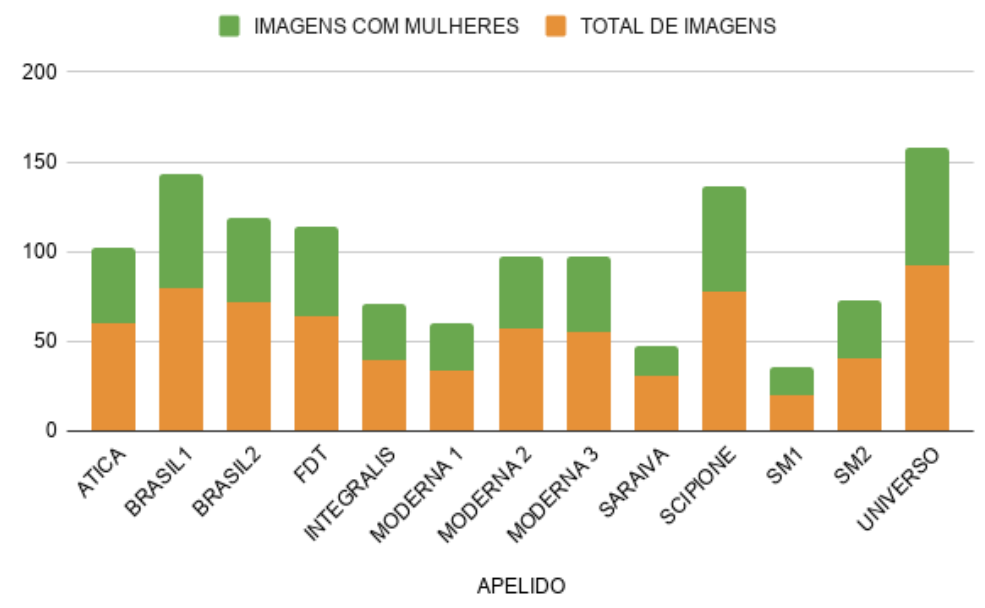

Fonte: Elaborado pelas autoras, 2021. 
Outro aspecto importante relacionado às imagens é o fato de que não necessariamente as mulheres estão sempre associadas a homens - aspecto que não foi inicialmente pensado na metodologia, mas que se destacou ao longo da análise. No livro Ática, por exemplo, 38\% das figuras contêm somente mulheres e $28 \%$ são exclusivamente de homens. Esse padrão se repete ao longo das editoras. Isso é importante porque reforça a ideia de que mulheres podem estar em situações diversas sem a tutela masculina. Na Figura 2, por exemplo, meninas jogam basquete sem precisar da supervisão de um homem, o que por si só já passa uma mensagem de independência.

Ao se tratar da quantidade de autoras em função do total de autores, a porcentagem obtida atesta que, nesse quesito, a igualdade de gênero está significativamente presente. Destaca-se a ausência de mulheres somente em 2 livros, os quais foram elaborados por um único autor. Dos 52 idealizadores dos 9 livros, 31 são mulheres ( 60\%), sendo dois deles elaborados apenas por autoras.

Gráfico 2 - Quantitativo da autoria dos livros classificados por gênero

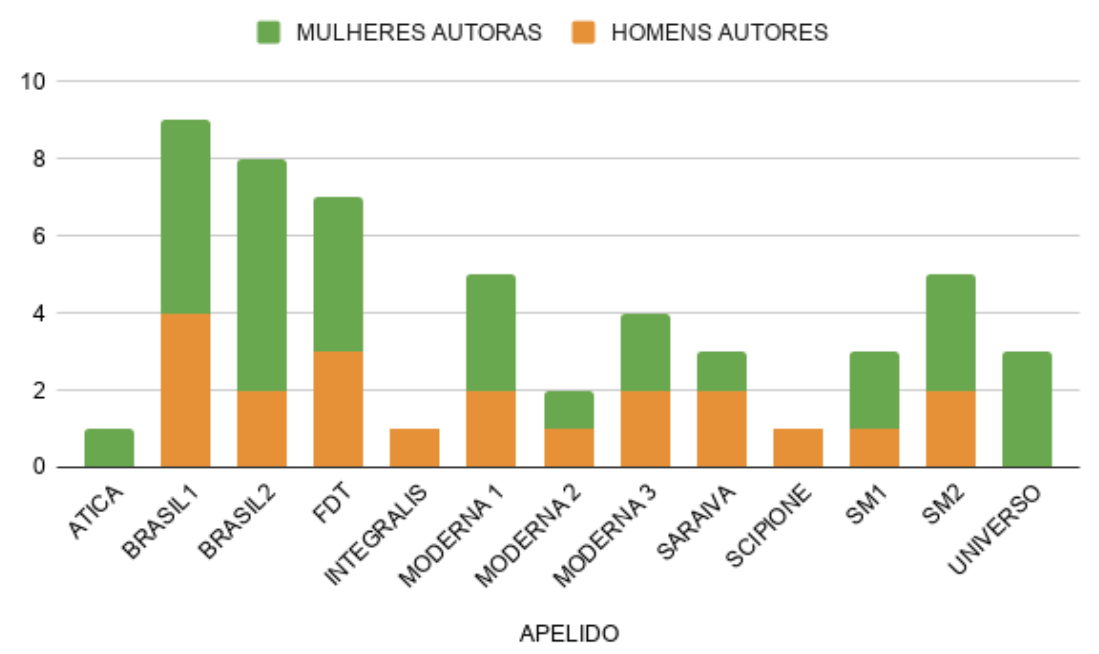

Fonte: Elaborado pelas autoras, 2021.

$\mathrm{Na}$ equipe técnica, $60 \%$ das pessoas que participaram da produção dos materiais eram mulheres. Isso reflete as estatísticas do setor de serviços no Brasil (IBGE, 2010) e mostra uma preocupação em compor times mais igualitários. Considerando que a porcentagem ideal é $50 \%$, todos os livros se mantiveram com percentuais bem próximos, conforme mostrado no Gráfico 3. Porém, é importante ressaltar as limitações dessa análise, pois igual quantidade, ainda que positiva, não se reflete em equidade salarial, que precisa de outros dados para ser analisada.

Embora os parâmetros analisados até então sejam positivos no tocante à igualdade de gênero, as citações e referências indicam um verdadeiro problema na reprodução das produções femininas. Das 281 citações, somente 66 eram relativas a mulheres ( $23 \%)$. Ademais, elas compreendem apenas 166 dos 484 trabalhos referenciados ( 34\%). Esse resultado está em completo desacordo com a produção acadêmica feminina. Segundo dados do IBGE, $58 \%$ das pessoas com nível superior completo no Brasil são mulheres (IBGE,2010). Estas são também 49\% das autoras de trabalhos científicos (FAPESP, 2017) e responsáveis por $72 \%$ da produção intelectual nacional (TOKARNIA, 2019). Analisando mais estritamente a produção relacionada a este trabalho, ou seja, Ciências da Natureza, vemos que a porcentagem homens/mulheres é equivalente (26\%/23\%, respectivamente). Diante desses dados, esperava-se que mulheres fossem pelo menos igualmente citadas e referenciadas, o que não se traduz na realidade das obras analisadas. 
Gráfico 3 - Distribuição da equipe técnica

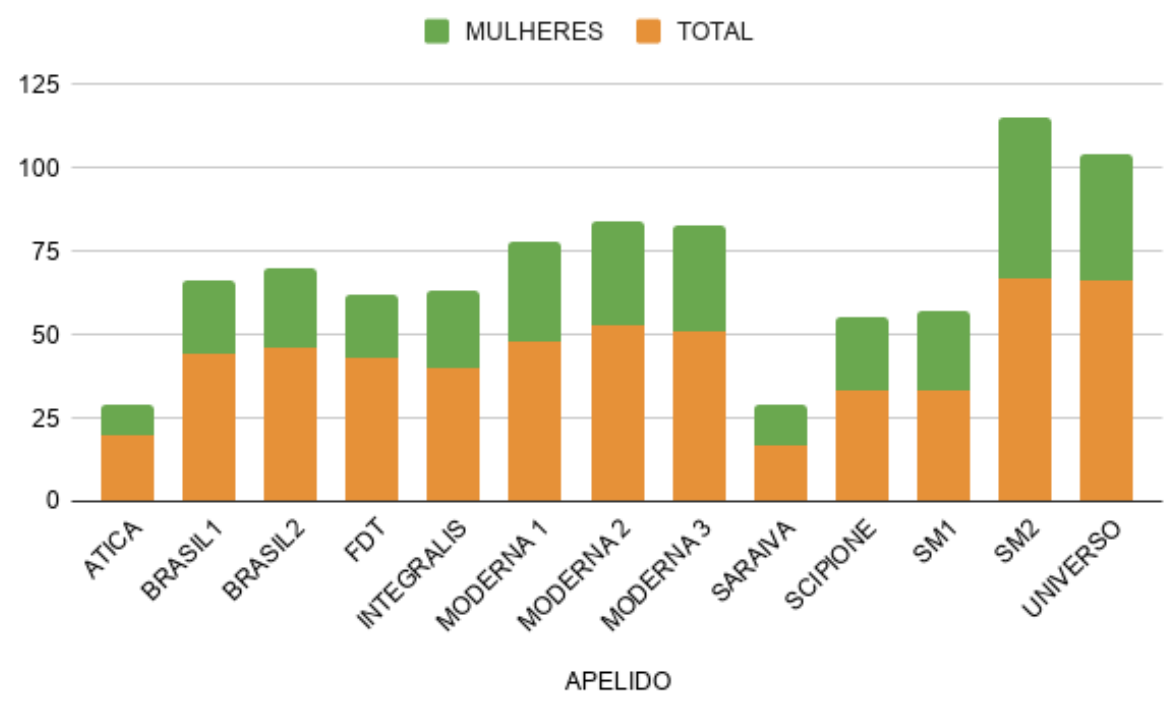

Fonte: Elaborado pelas autoras, 2021.

Durante o estudo dos livros, um outro parâmetro não previsto inicialmente se tornou relevante: a representação de ativismo feminino nos livros. Isso se dá porque tal ativismo é um tópico presente e valorizado na maioria das obras. Em 9 dos 13 livros, essas meninas, geralmente jovens, são citadas como exemplos de protagonistas nas lutas ambientais e educacionais, principalmente Greta Thunberg (6) e Malala Yousafzai (3). Isso pode ser interpretado como um fator positivo e atual, uma vez que os jovens podem se sentir representados e motivados por essas figuras que têm idades próximas às suas.

No módulo "Protagonismo Juvenil" do livro Scipione, encontra-se uma página (p. 43) inteira a respeito do ativismo jovem. Junto a Severn Suzuki, Greta Thunberg é lembrada pelo seu movimento em torno da temática ambiental. A sueca de 18 anos ficou conhecida pelo mundo ao chamar a atenção de líderes mundiais pedindo por atitudes imediatas no que diz respeito às mudanças climáticas. Além de sua biografia, seu discurso e a importância do seu movimento são destacados na sessão.

Com todos os parâmetros propostos estudados e os dados levantados, prossegue-se para a conclusão que será apresentada em maiores detalhes na próxima seção.

\section{CONCLUSÃO}

O objeto de estudo deste trabalho é a representação feminina nos novos LDs disponibilizados pelo PNLD em 2021 na área de projetos integradores em Ciências da Natureza. Para isso, realizou-se um estudo de caso das treze obras selecionadas no programa.

O primeiro parâmetro analisado foi a apresentação das mulheres na forma de imagens; se era frequente e positivo. Nossa análise mostrou que as respostas foram "sim" para ambas as perguntas, com 73\% das imagens apresentando mulheres e nenhuma representação negativa e estereotipada foi identificada. Isso já caracteriza um avanço na representatividade quando comparada com trabalhos similares recentes, como de Rosa e Silva (2015), realizado apenas seis anos atrás e que constatou apenas $21 \%$ de imagens deste tipo. 
No tocante à participação feminina na produção desses materiais também encontrou-se um equilíbrio tanto entre autores (60\%) quanto entre a equipe técnica (60\%). Embora não seja possível através dos nossos dados investigar se há equidade financeira entre os profissionais de ambos os gêneros, tal resultado em si já é positivo pois mostra equidade na quantidade.

Outro resultado positivo que surgiu durante a análise foi a averiguação da ênfase em ativistas em geral, mas principalmente mulheres jovens contemporâneas, nos LDs. Elas são citadas de maneira positiva na maioria deles (70\%) e apresentam de certa forma uma mudança na perspectiva desses livros, os quais tradicionalmente buscavam maior ênfase em conquistas passadas. Isso está de acordo com a diretriz desse tipo de obra - projeto integrador - que visa um novo relacionamento com o conhecimento, onde o estudante vê a si próprio como protagonista.

Apesar desses avanços, há ainda pontos a serem melhorados. O que mais chama atenção é a discrepância entre as citações e referências a mulheres em todos os livros, mesmo aqueles escritos por mulheres. No geral, a participação feminina se limitou a $23 \%$ das citações e $34 \%$ das referências, enquanto no Brasil elas são responsáveis por $72 \%$ da produção acadêmica (TOKARNIA, 2019). Esse resultado nos mostra uma realidade onde a palavra e o trabalho da mulher ainda são diminuídos, 0 que leva à pensar que os séculos de repressão e omissão da intelectualidade feminina ainda são refletidos nos dias atuais na forma da não valorização de seu trabalho.

À vista disso, entende-se que a representatividade de mulheres nos livros didáticos de projetos integradores em Ciências da Natureza avançou no tocante ao visível (fotos, equipe, autores) mas ainda pouco valoriza a Ciência feminina propriamente dita. Vê-se então a necessidade de uma reflexão sobre os motivos que levam mulheres a serem menos citadas, o que possibilitará ainda mais melhorias na elaboração desses materiais e mudanças estruturais de fato.

Além disso, os resultados obtidos mostram que a investigação de LDs é uma importante ferramenta de reflexão dos papéis de gênero. Dessa forma, recomenda-se a expansão dessa análise para livros de outras áreas a fim de verificar se os avanços e os problemas aqui levantados nos LDs são específicos da área de Ciências da Natureza ou se repetem em todas as áreas do conhecimento.

\section{REFERÊNCIAS}

BELMIRO, Celia Abicalil. A imagem e suas formas de visualidade nos livros didáticos de Português. Educação \& sociedade, v. 21, n. 72, p. 11-31, 2000.

BIANCHI, Madge. et al. Representações de gênero: como as mulheres cientistas e suas contribuições são representadas nos livros didáticos de Física, Química e Biologia. In: Anais SECITEC 2019 - Semana da Ciência e Tecnologia, v.4, n.1, 2019, Luzerna, SC.

BIANCHI, Madge. Representatividade das mulheres na ciência: visibilidade através do livro didático de física. In: XVIII Encontro de Pesquisa em Ensino de Física - 2020, 2020, Luzerna, SC.

BRASIL. Base Nacional Comum Curricular. Brasília, 2017. Disponível em: <http://basenacionalcomum.mec.gov.br/images/BNCC_20dez_site.pdf>. Acesso em: 12 mai. 2021.

DIEDRICH, Bruna. "Falar em filósofas é falar em revolução": representação feminina no ensino de Filosofia. Monografia (Graduação) - UFRGS, Porto Alegre - RS: 2018. 
DINIZ, Cristiane. Desigualdades e reconhecimentos: memórias de uma escrita feminina e afro-brasileira. Dissertação (Mestrado) - UNIMONTES, Montes Claros - MG: 2014.

FAPESP, Em busca de equilíbrio. Revista Fapesp, edição 254. São Paulo, 2017.

FARIAS, Micarla Lopes, FAHEINA, Evelyn Fernandes Azevedo, Análise Semiótica de Imagens do Livro Didático de Língua Portuguesa, TOKARNIA, Mariana. Mulheres assinam 72\% dos artigos científicos publicados pelo Brasil. RDIVE, João Pessoa, v.3, n. 2, p. 5-25, 2018.

IBGE, Estatísticas de Gênero. Brasília, 2010. Disponível em:

<https://www.ibge.gov.br/apps/snig/v1/?loc=0\&cat=-1,1,2,-2,-27,112,113,114,128\&ind=4741>. Acesso em: 12 de mai. 2021.

LIMA, Betina Stefanello. Teto de vidro ou labirinto de cristal? As margens femininas das ciências. Dissertação (Mestrado) - Universidade de Brasília, Brasília, 2008.

MAGALHÃES, W. DE A. M.; PEREIRA, A. L. S. O uso da aprendizagem baseada em problemas no ensino técnico: projetos integradores como experiência interdisciplinar. Revista de Estudos e Pesquisas sobre Ensino Tecnológico (EDUCITEC), v. 5, 12, 2019.

ONU MULHERES. Princípios de empoderamento das mulheres. 2017. Disponível em: $<$ https://www.onumulheres.org.br/wpcontent/uploads/2016/04/cartilha_ONU_Mulheres_Nov2017_digital.pdf>. Acesso em: 12 de mai. 2021.

PRODANOV, Cleber Cristiano; DE FREITAS, Ernani Cesar. Metodologia do trabalho científico: métodos e técnicas da pesquisa e do trabalho acadêmico. 2a Edição. Editora Feevale, 2013.

MAGALHÃES, A. F., de ANDRADE, C. R., SARAIVA, L. A. S. Inclusão de Minorias nas Organizações de Trabalho: Análise Semiótica de uma Estratégia de Recrutamento de uma Multinacional de Fast Food. Teoria E Prática Em Administração, 2017.

MEC, Guia Digital do PNLD, Brasília, 2021. Disponível em <https://pnld.nees.ufal.br/assetspnld/guias/Guia_pnld_2021_proj_int_vida_Apresentacao.pdf>. Acesso em 10 de abr. 2021

ROSA, Katemari; DA SILVA, Maria Ruthe Gomes. Feminismos e Ensino de Ciências: análise de imagens de livros didáticos de Física. Revista Gênero, v. 16, n. 1, 2015.

SIQUEIRA, Gisele. "E onde estavam as mulheres?" a presença das mulheres nos livros didáticos de História do ensino médio (2015 - 2017). Trabalho de Conclusão de Curso (Licenciatura em História) - Instituto de Ciências Humanas, Comunicação e Artes, Curso de História, Universidade Federal de Alagoas, Maceió, 2019.

TOKARNIA, Mariana. Mulheres assinam 72\% dos artigos científicos publicados pelo Brasil. Agência Brasil. Brasília, 2019.

Submissão: 05/07/2021

Aceito: 11/10/2021 